\title{
Integration Of Diversity In Multinational Companies
}

\author{
Amel Mohamed Kriw \\ Phd.candidate \\ DOI: 10.29322/IJSRP.11.08.2021.p11683 \\ http://dx.doi.org/10.29322/IJSRP.11.08.2021.p11683
}

\begin{abstract}
Workforce diversity occurs when there is a wide range of people with different histories, different nationalities and ages. Diverse and inclusive organizations bring innovative results. Technological industry still struggles with diversity and inclusion, often failing to attract diverse talent due to problems integrating in the workplace. For organizations that want to shape their diversity and inclusion programs and policies, change can be challenging and rewarding. Most companies make changes to bring business value, and many who launch diversity and inclusion initiatives state that companies with more diverse teams outperform those with a more homogeneous workforce. Studying the integration and impact of diversity, ie diversification, of human resources and their potentials in companies and companies operating in world markets, human resources are the most relevant and constitute the real strength of the company.
\end{abstract}

Index Terms- human resources, diversification, management, integrating diversity, competitive advantage

\section{INTRODUCTION}

$I^{2}$ order for an organization to survive in the market, it is necessary to constantly develop and grow. In modern business conditions, some of the assumptions for the organization to be stable in the long run are: the development of organizational configuration, diversification of activities and increasing the size of the organization. Diversification represents diversity and the acquisition of different knowledge and skills. In a certain sense, the notion of diversification can be interpreted as the opposite of specialization, in the sense of acquiring greater and narrower knowledge and skills.

The word diversification originates from the Latin word diversificatio, diversificatoinis, which in translation means breadth, diversity, comprehensiveness. The term diversification is most often used in economics or business management. Within these areas, the term diversification implies the effort of a company to expand its business, services or activities to a larger number of fields, customers, countries or products. Regarding the reasons for respecting and integrating diversity in employment, it can be multiple. For example, the main reason is to respect and comply with the law and existing legal regulations. Also, there are important economic reasons, which relate to the movement of labor, reducing the risks and losses due to discrimination, the creation of new markets. Further, ethical reasons, which strive for the absolute inadmissibility of discrimination, then social reasons, which enable social inclusion and equal opportunities.

These differences should not be viewed as a disadvantage, but as an advantage and potential from which new values and additional quality can emerge, provided that they are adequately treated and that such human resources are properly managed. This attitude applies not only to multinational companies, but also to all other companies that today want to survive in any market (local or global).

\section{STRATEGIES FOR INTEGRATING DIVERSITY}

There are several strategies for integrating diversity in multinational companies:

1. Establishing a sense of belonging for all - In order for each individual to present their best, a sense of belonging must first be established. Connecting with an organization or group of people that makes you feel like belong there and being what you realy are, not only results in greater engagement and creativity in the workplace, it is also a psychological need. But these changes take time and cannot be realized in a short period of time. It is very important to share best practices and be open for trying new things.

2. Empathic leadership - Diversity and inclusion are often treated as one initiative exclusively belonging to human resources. For real change to happen, each individual leader must value belonging, both intellectually and emotionally. Part of this process requires empathy; each person remembers the time when they were excluded, embarrassed, interrupted, etc., so that they can apply those lessons from the outside. Leaders must feel this and only then they can identify that others feel excluded.

3. A top-down approach is not enough - this approach is characterized by coherence, not commitment. From senior executives to first-line employees, each individual must see and understand their role in the company's culture. This means identifying differences in the experience and values of employees across the organization to make the change relevant to each person. Also, it is necessary that permanent changes must activate different parts of the system in different ways - from the top down, from the bottom up and in the middle.

4. Organizational goals - employment goals can increase diversity, but will not automatically create an inclusive culture. In order to retain and raise top talent, it is crucial to honestly look at the experience of employees, and to focus on creating conditions that promote inclusion on a daily basis and designing ways to measure its impact. Organizations must adapt their processes to rank different and inclusive behaviors. For example, in situation of meetings: Who is invited? Who can speak and how often? Are you omitting someone whose contribution would be valuable? Everything must be seen through a prism: Whether the conditions are created for each person to contribute in their own unique, meaningful way and at the same time feel safe and secure by doing so ? If we recognize a situation where this is not the case, an effort should be made to change that. It also means 
understanding how your teams work the best and when tension and disharmony are actually helpful.

5. Inclusion is not a one-time training - It is not enough to teach employees what it means to be inclusive. Like any form of behavior change, inclusion requires individuals to identify key moments in which they can build new habits or "micro behaviors" (everyday actions that can be practiced and measured). And when these habits are applied in an environment that supports honest conversations and healthy tension, real changes become possible. So for example, one way to do this is to identify changes within the organization, both outside the executive or management level. Also, employees need to be taught skills and information that will help them create positive change in their departments, teams and work groups. This is much more effective than one-time training.

6. Strengthening connections - People react with fear and mistrust when their beliefs are challenged in whole or in part. While fear can be a powerful motivator, it also encourages people to narrow their perspective - the opposite desired effect for creating a more inclusive workplace. Finding ways to frame challenges through the prism of opportunity and elevating the power of shared experiences creates greater potential for positive change. It is necessary for managers not only to point out where there is room for improvement, but also to highlight moments of success and celebrate them with their employees.

7. Helping individuals progress - Norms, power structures and inequalities in society can be easily integrated into an organization - by optimizing the recruitment, training and rewarding of people who "fit". Creating a culture in which each individual can give their full potential requires exploring the systems and processes in the organization to discover key points, and then finding ways to overcome them. Organizations must be able to identify and "live" their organizational values.

8. Analyzing own brand - the brand and culture of the organization are closely related. The products and services that are marketed reflect the value of the organization. On the way to building a more inclusive organization, it is important to consider the relationship between what is happening inside and outside your company. That is why it is necessary to have answers to some of the questions, namely: What does the brand say about your culture? What experiences are left out or misunderstood from your base or your customer's base? Diversification is not just an initiative or a program. It requires investment both from the oldest to the youngest person in the organization.

\section{The role and importance of diversified teams in multinational companies}

Multinational companies conduct their business activities in a number of countries around the world, through their branches. "A branch of a multinational company is a partially autonomous entity with entrepreneurial potential, operating within a complex competitive arena consisting of an internal environment (other branch offices, internal consumers and internal suppliers) and an external environment (consumers, suppliers and competitors)."1

\footnotetext{
1 Birkinshaw Julian, Hood Neil, Young Stephen: "Subsidiary Entrepreneurship, Internal and External Competitive Forces, and Subsidiary Performance", International Business Review, 14(2)/2005, 228.
}

"Branch offices in the foreign country (or host country) are unique organizational units that must simultaneously adapt to both internal and external environment in order to be competitive in both."2 Human resources are a prerequisite for the success of all companies, especially multinational companies, that is why human resource management resources has an increasingly important role to play in creating and maintaining the competitive advantage of multinational companies.

A multinational companies directs its employees to work in foreign branches, for a certain period of time, all depending on the goal of the work they will perform. There are several types of international engagements in multinational companies, namely: short-term and long-term engagement, non-standard alternative types of international engagement (frequent flyer and "traveling" engagement), then contract engagement, rotational engagement and finally virtual engagement.

Short-term engagements are engagements of a determined duration, usually lasting from one month to one year. They often involve international engagements of a technical nature with the aim of resolving specific problems or technical issues or engagements aimed at overseeing work on a specific project. During these engagements, the family of the employee usually does not move to a foreign country. Short-term engagements are mainly used for the purpose of transferring skills to a foreign branch and, to a lesser extent, for the development of the managers themselves.

"Traveling" engagement is an engagement in which an employee travels from their home country to a foreign country for work, usually once a week or once every two weeks. Bearing in mind that the employee's family remains in the home country, this type of international engagement enables overcoming various problems related to the relocation of the employee's family to a foreign country, which otherwise occur in long-term engagements. In the case of frequent flyer engagements, the employee often goes on business trips but does not move to another country. This type of international engagement is mainly used for the purpose of exercising managerial control over a foreign branch.

Rotational engagement means international engagement in which an employee travels from his home country to a foreign country for work for a short pre-defined period, and then takes a break in his country (eg. work on an oil platform). Contractual engagement is used when a company needs to send an employee to a foreign country that is crucial for an international project for a period of six months to a year (eg. one of the areas in which employees are engaged in this way is research and development). Virtual engagement implies a form of international engagement in which the employee is not transferred to a foreign country, but from the home country virtually manages a working group in a foreign country, where communication takes place mainly through electronic media. This type of engagement is often used for regional positions, where the employee is located in a regional

${ }^{2}$ Colakoglu Saba, Tarique Ibraiz, Caligiuri Paula: "Towards a Conceptual Framework for the Relationship between Subsidiary Staffing Strategy and Subsidiary Performance", International Journal of Human Resource Management, 20(6)/2009, 1294 
center in one country, and coordinates the activities for which he is in charge in all countries in a particular region. ${ }^{3}$

Another benefit of diversity in the workplace is that homogeneous teams seems smarter. Working with people who are different from you can cause your brain to overcome the stagnant way of thinking and sharpen its performance.

The following text shows the advantages of diversified teams in multinational companies:

- Focus on facts - When there are more people of different backgrounds in one team, then they can change the behavior of the social majority of the group in ways that lead to improved and more accurate group thinking. "In a study published in the Journal of Personality and Social Psychology, scientists assigned 200 people to fake jury commissions with six people whose members were either white or four white and two black participants. The people were shown a video from the trial of a black man and white victims. Then they had to decide whether the defendant was guilty. It turned out that the various chambers presented more facts related to the case than the homogeneous chambers and made fewer factual errors as they discussed the available evidence. If errors did occur, they are more likely to be corrected during the review. One possible reason for this difference was that white jurors on various panels more accurately referred to the evidence. Other studies have yielded similar results. In a series of experiments conducted in Texas and Singapore, scientists put financially literate people in simulated markets and asked them to value stocks. Participants were housed in ethnically diverse or homogeneous teams. The researchers found that individuals who were part of different teams were $58 \%$ more likely to value stocks correctly, while those in homogeneous groups were more prone to price errors, according to a study published in the journal PNAS." "Therefore, different teams are more likely to constantly re-examine the facts and remain objective. In addition, diversified teams can have more control over each member's actions, keeping shared cognitive resources sharp and alert. By breaking the homogeneity in the workplace, you can allow employees to become more aware of their own potential biases - ingrained ways of thinking that can otherwise blind them to sometimes, key information, and this can lead them to make mistakes in decision-making processes.

- Better innovation - If an organization wants to be competitive, it needs to change constantly. For example, one way to transform an organization and its products may be to employ more women and culturally diverse team members. "In a study published in the Journal Innovation: Management, Policy \& Practice, the authors analyzed the level of gender diversity in research and development teams from 4,277 companies in Spain. Using statistical models, they found that companies with more women were more likely to introduce radical new

\footnotetext{
${ }^{3}$ Tatjana Ratković, Ekspatrijati u multinacionalnim kompanijama, Fakultet organizacionih nauka, Univerzitet u Beogradu, Beograd, 2014. godine, strana 226.
}

innovations to the market over a two-year period. In another study, published in the Journal Economic Geography, the authors concluded that increased cultural diversity is a boon for innovation. They pooled data on 7,615 firms that took part in the London Annual Business Survey, a questionnaire conducted with executives in the British capital that asks a number of questions about the performance of their companies. The results found that companies run by culturally diverse leadership teams were more likely to develop new products than those with homogeneous leadership. and with the aim of avoiding harmonization, which discourages innovative thinking." 5

If the organization hires employees of different genders, races and nationalities, then it creates greater chances for strengthening the common intellectual potential. Creating a more diverse workplace helps employees rethink their assumptions. Also, the organization should nurture inclusive practices so that all employees feel that their opinion is valued and can be heard.

\section{HUMAN RESOURCE DIVERSIFICATION PERFORMANCE IN MULTINATIONAL COMPANIES}

As multinational companies expand their international operations, they become more exposed and gain experience in relation to the different cultures, customs and practices in each country in which their subsidiaries are established. On the other hand, multinational companies are also spreading this practice. Multinational company have to decide whether to globally standardize their approach to human resource management or, on the other hand, to locally adapt human resource management.

That is why the issue of convergence versus divergence is the main concern of all large organizations. Some human resource management practices are very sensitive to institutional and cultural differences. That is why one of the tools of human resource management appears in practice - performance assessment. Performance assessments are tools that ensure the consistency of information between the headquarters of a multinational company and its subsidiaries. Also, by applying this tool in practice, control is maintained and the desirable behavior of employees working in branches around the world is encouraged. However, the degree of standardization of performance assessments is debatable.

Performance appraisal is a key element of performance management and can be defined as the process of identifying, observing, measuring and developing human resources in organizations. International Performance Assessment refers to the process of human resource management that allows multinational companies to assess and continuously improve employee performance, in order to achieve clearly defined goals that serve to improve the overall progress of the company. The use of standardized performance assessment can lead to a reduction in inconsistencies in information between a parent company and a subsidiary in a foreign country. However, it is an extremely complex process, as there is no written method of assessing the

\footnotetext{
${ }^{4}$ https://hbr.org/2016/11/why-diverse-teams-are-smarter

${ }^{5}$ https://hbr.org/2016/11/why-diverse-teams-are-smarter,
} 
performance of employees in remote countries. Environmental factors and differences in subsidiaries and their countries, such as differences in social, legal, economic, or physical requirements, can greatly influence the performance appraisal process. There are many other variables to consider when evaluating in another country, such as language barriers, differences in values, and differences in cultures that make the process even more difficult.

Hence, any person who assesses the performance of an employee in a subsidiary should take into account intercultural interpersonal qualities, the employee's sensitivity to foreign norms, laws and customs, and the adaptability of employees to uncertain and unpredictable conditions that may arise. International performance appraisal is a topic that attracts the attention of practitioners and academics; however, most research has focused on assessments of immigrants' performance. The standardization of performance appraisal practices in foreign subsidiaries versus the localization of these practices in order to adapt to the dependent country is an important discussion that has been discussed in the literature. Despite the fact that multinational companies strive for consistency in their human resource management in subsidiaries, these practices are shaped by local customs, and subsidiaries usually employ employees from the host country's labor market, making it difficult for them to deviate from local norms.

Performance assessment methods also vary from country to country, from culture to culture. When it comes to collectivist and long-distance cultures, the method used is usually informal and unsystematic and involves subjective factors. For example, in Chinese culture, it is considered inappropriate for people in inferior positions (subordinates in the workplace) to express opinions contrary to those in higher positions. Such a method is therefore more suitable for cultures with a small distance of power and individualistic values, than for collectivist and long-distance cultures. Therefore, different cultures may understand performance assessments differently. For example, Arab culture is classified as high context and uses implicit messages. Employee performance could be interpreted or evaluated in different ways due to differences in cultures, values, and belief systems. For example, what is right or wrong and good or bad behavior could be interpreted differently by the individual who collects and evaluates the data, and that is because of cultural differences.

American-style performance appraisal is usually goal management. Employees work together with their boss to set goals, assess their own performance and comment on whether the boss helped them achieve their goals or made things difficult for them. However, in eastern countries, where open responses from older people are not discouraged, where admitting mistakes (by employees) or criticizing (by employees) is a loss of identity, and where criticizing the boss in front of that person would be considered a form of organizational suicide, performance would be different in subsidiaries operating in such countries. On the other hand, the person giving feedback in collectivist cultures should be in a high position, as well as respected for his wisdom and expertise. Feedback should also target the group, not the individual.

In collectivist cultures, group loyalty is also more important than productivity. A group may not like highperforming employees in a group, which means that they disturb group harmony or provoke jealousy.

\section{CONCLUSION}

Diversification represents diversity and the acquisition of different knowledge and skills. In a certain sense, the notion of diversification can be interpreted as the opposite of specialization, in the sense of acquiring greater and narrower knowledge and skills.

Sensitivity to the problems of minorities, marginalized and deprived groups in today's society is growing. Trade unions can make a significant contribution to awareness-raising by supporting negotiations and social dialogue by advocating for diversity policies, while employers must create the conditions for their organizations to respond appropriately and effectively to social change and the new labor market situation and implement high ethical standards. private, public or non-profit employment sector.

The feature of multinational companies is that they conduct their business activities in a number of countries around the world, through their branches. As human resources are a prerequisite for the success of all companies, especially multinational companies, human resource management has an increasingly important role in creating and maintaining the competitive advantage of multinational companies. As multinational companies expand their international operations, they become more exposed and gain experience in relation to the different cultures, customs and practices in each country in which their subsidiaries are established.

If a company improves the management of human resources through organized and continuous improvement of their potentials, then there will be an improvement in the company's performance, profitability, productivity, product quality, etc.

\section{AUTHORS}

First Author - Amel Mohamed Kriw Phd.candidate 